\title{
Pollination of Sedirea japonica (Orchidaceae) by Bombus diversus diversus (Hymenoptera: Apidae)
}

\author{
KenJI SUETSUGU ${ }^{1}$ and KoJI TANAKA ${ }^{2}$ \\ ${ }^{1}$ Graduate School of Human and Environmental Studies, Kyoto University, Yoshida-Nihonmatsu-cho, Sakyo, Kyoto 606-8501, \\ Japan; e-mail: kenji.suetsugu@gmail.com \\ ${ }^{2} 349$ Yamamoto, Minami, Kokura, Kita-Kyushu, Fukuoka 803-0264, Japan; e-mail: colobockle@m3.dion.ne.jp
}

Key words. Hymenoptera, Apidae, Bombus, bumblebee, orchid, Sedirea japonica, pollinator, Xylocopa

\begin{abstract}
There are no records of the pollinators of many orchids even though the Orchidaceae are often cited as the example of an intimate relationship between plants and their pollinators. We recorded the insects visiting the flowers of Sedirea japonica that might be pollinators of this species by using digital cameras to take photographs automatically of the flowers. Based on our evidence of pollinia being attached or removed from flowers, we conclude that Sedirea japonica can be pollinated by Bombus diversus diversus.
\end{abstract}

\section{INTRODUCTION}

The family Orchidaceae is one of the most species-rich and morphologically diverse plant families on earth. The floral diversity of orchids has long intrigued evolutionary biologists (Darwin, 1862; Jersakova et al., 2006; Ramirez et al.). Adaptation to specific pollinators is an important attribute of the impressive floral diversity of orchids (Cozzolino \& Widmer, 2005). Of all the orchid species, an estimated $60 \%$ are pollinated by only one species of insect (Tremblay, 1992), which is both a prezygotic and ethological mechanism of importance in determining the reproductive isolation of species (Cozzolino \& Widmer, 2005).

However, the pollination of orchids is relatively rarely recorded under natural conditions (Widmer et al., 2000). Because of the low proportion of flowers visited by pollinators, it is difficult to directly observe orchid pollination (Neiland \& Wilcock, 1998; Tremblay et al., 2005). However, an understanding of the reproductive biology of orchids could help determine whether a failure in the recruitment cycle is limiting their reproductive potential and constraining their population growth (Gale, 2007). When integrated with data on other factors of their life history, this information could give an estimate of the persistence of populations at particular locations (Gale, 2007). Therefore, knowledge of pollination biology is necessary when planning measures to conserve endangered species of plants (Roberts, 2003; Giovanetti et al., 2007).

The aesthetic beauty and spectacular floral diversity of orchids has long been appreciated, and Eastern Asian countries such as Korea, China and Japan have a long history of cultivating these plants (Cribb, 1997). Sedirea japonica is an orchid indigenous to the southern part of Japan and Korea and it is recorded that this orchid was cultivated on the main Okinawa island during the Ryukyu Dynasty as early as 1719 by Hsu in a report of an envoy to Chuzan. This species of orchid was commonly used as a tribute or gift in Japan and China. However, it is now thought that after years of excessive and reckless harvesting for horticulture, the wild $S$. japonica that once grew on the main island of Okinawa is now extinct. There are populations on other islands, which consist of only small numbers of $S$. japonica in the upper parts of trees, whose survival is possibly mainly due to their inaccessibility. Its status is listed as "endangered" in Japan, which means that in the near future, there is a high risk of extinction (Environment Agency of Japan, 2000). In order to meet horticultural needs, $S$. japonica has been successfully propagated (Cui et al., 2008). However, its life history in natural habitats is still poorly understood.

Taxonomically, S. japonica was once placed in Aerides. However, Garay \& Sweet (1974) recognized its distinctiveness and transferred it in its own genus, Sedirea, which is an anagram of Aerides (Garay \& Sweet, 1974). However, a close relationship between Sedirea and Aerides is not confirmed by molecular studies (Topik et al., 2005; Kocyan et al., 2008), which indicate that Sedirea could be the sister taxon to all other Aeridinae (Kocyan et al., 2008). Approximately 1,350 species in 103 genera are recorded in the subtribe Aeridinae, which is a large and diverse group of orchids (Topik et al., 2005). Therefore, information on the pollination biology of $S$. japonica is important because it may be a plesiomorphic character of the subtribe Aeridinae. Here, we recorded the insects visiting the flowers of S. japonica in order to both clarify the intimate plantpollinator interaction and plan a comprehensive conservation strategy for this orchid. To overcome the difficulty of recording the insects visiting the flowers, we used waterproof digital cameras that took photographs automatically at intervals.

\section{MATERIAL AND METHODS}

Sedirea japonica is an epiphytic orchid with glossy dark green leaves. The petals and column of the flower of Sedirea japonica are greenish white. Although the petals and dorsal sepal are completely greenish white, the bases of the lateral sepals are purple-brown. Rose-coloured blotches mark the margin of the white labellum, perhaps functioning as nectar guides (Fig. 1A, B). The greenish white spur curves forward and its length is approximately twice its width at the widest point (Stpiczyńska et al., 2011).

The pollination biology of $S$. japonica was carried out at Kitakyushu City, Fukuoka Prefecture in early July. At the study site, plants of S. japonica were growing on Quercus glauca at a height of ca. $5 \mathrm{~m}$. The study site was originally a dense, broadleaved evergreen forest dominated by Castanopsis sieboldii and Machilus thunbergii. Due to forestation, however, it is presently dominated by Phyllostachys heterocycla. Because our preliminary investigation revealed that pollinia were removed during daytime, we recorded the insects that visited the flowers of two 

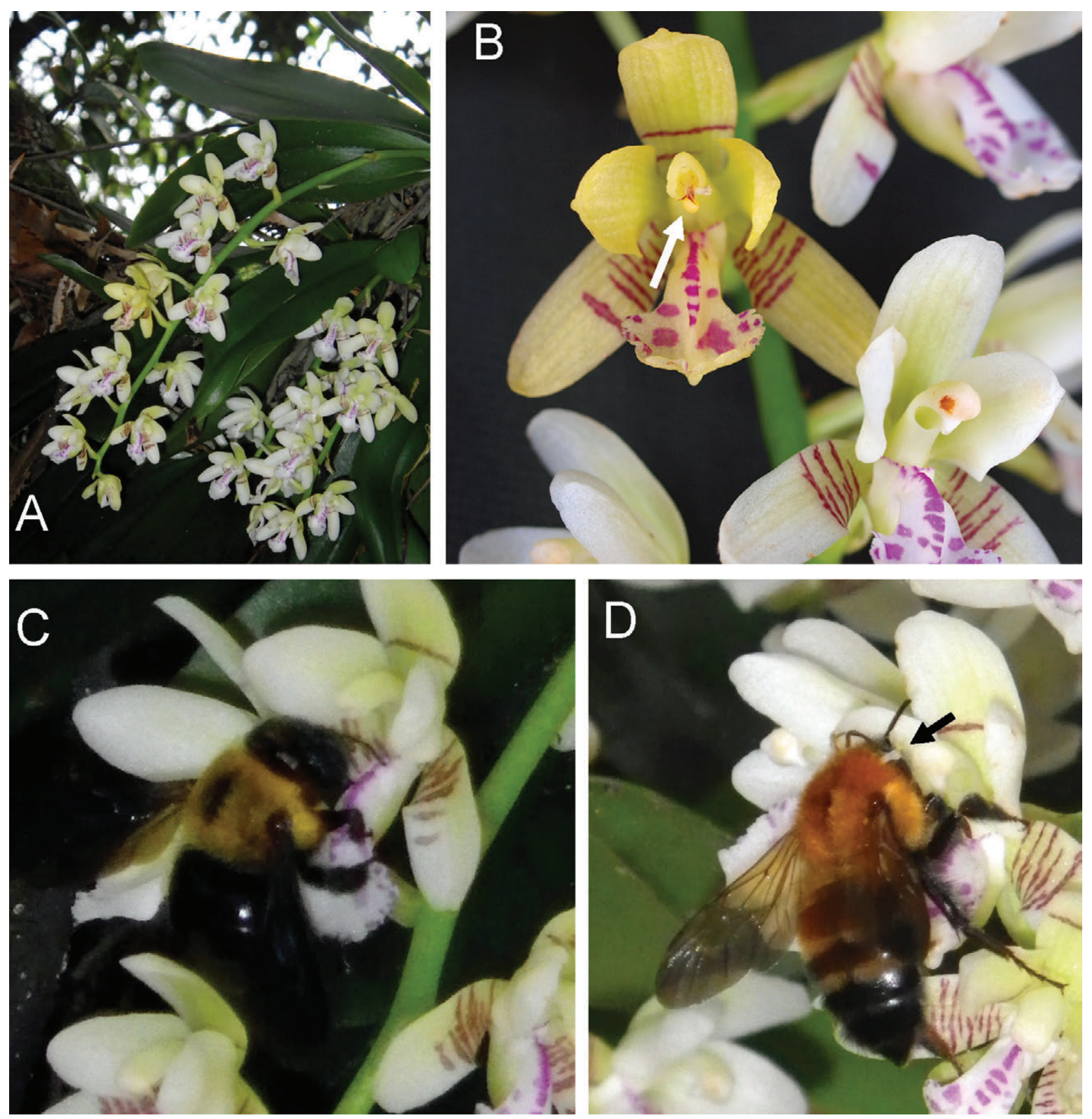

Fig. 1. Flowers and insect visitors of Sedirea japonica. A - flowering plant; B - pollinated flower. Pollinium is indicated by the arrow, C - Xylocopa appendiculata circumvolans visiting a flower and D - Bombus diversus diversus visiting a flower. The viscidium attached to this bee is indicated by the arrow.

plants of Sedirea japonica during the day using two waterproof digital cameras (Optio WG-1, Pentax, Japan). Photographs were taken automatically at intervals of 10-20 s, over a period of $14 \mathrm{~h}$ between July 8 and July 10, 2012.

When orchids are pollinated, it is possible to measure both female and male reproductive success, because the deposition and removal of pollinia are easily scored and identified in the field, and are a good index of the number of visits by pollinators. The plants of $S$. japonica photographed were checked before and after they were photographed to determine whether pollen was removed or deposited on the flowers. Furthermore, the number of flowers from which pollen was removed (male reproductive success) or deposited on (female reproductive success) were counted at the end of flowering season for 39 flowers of the two photographed S. japonica plants.

\section{RESULTS AND DISCUSSION}

We found that the flowers of Sedirea japonica were only visited by females of Xylocopa appendiculata circumvolans (2 pictures, 2 visits; Fig. 1C) and workers of Bombus diversus diversus (12 pictures, 9 visits; Fig. 1D) over the 14-h period of this study. However, it should be noted that some of the visitors may spend very little time approaching and collecting resources from these flowers and thus their short visits (lasting less than $10 \mathrm{~s}$ ) may not have been recorded. The bees recorded visiting the flowers directly landed on the lip, and then adjusted their position so that they could enter the flower to forage for nectar 
within the spur. Both species were large enough to access the nectar within the spur. No pollen attachment/removal was recorded for the two visits by Xylocopa bees. However, as there were only two visits by Xylocopa bees it is not possible to say whether they are able to pollinate this orchid or not. In contrast, at least pollinia of two flowers were removed during the $14 \mathrm{~h}$ period of this study as there was a viscidium attached to the thorax of two of the $B$. diversus that visited the $S$. japonica flowers. This fact indicates that some pollinia were detached and therefore Bombus can successfully pollinate this orchid. In fact, we revealed the removal of pollinia twice and deposition of pollinia once in flowers visited by Bombus. Therefore, it is highly possible that $B$. diversus diversus is the pollinator of $S$. japonica, although we did not directly observe Bombus depositing a pollinium.

Because pollen grains are usually tiny, interval photography and video monitoring may not be suitable for identifying pollinators of plants other than orchids (Suetsugu \& Tanaka, 2013). In the family Orchidaceae, pollen grains are transferred in large groups within pollinia, which can easily be seen. The presence or absence pollinia are good indicators that pollen has been deposited or removed, respectively. Thus, a good technique to use when recording the insects visiting orchid flowers is video monitoring and/or interval photography. The present results clearly indicate that relatively large bees, such as bumblebees, pollinate Sedirea japonica but further studies on the specificity of this pollinator are needed.

Because Bombus is able to regulate its body temperature, bumblebees can pollinate flowers located in shaded and cold sites, i.e. under-stories of forest. The Bombus system of pollination, therefore, has evolved independently in Japanese temperate forests, and is important for orchids that grow where the light intensity is low (Sugiura, 1996; Sugiura \& Yamaguchi, 1997). Whilst epiphytes are probably exposed to higher levels of irradiance, compared to understory plants (Tsutsumi et al., 2011), $S$. japonica typically inhabits dense broad-leaved evergreen forest in which the endothermic Bombus may be at an advantage in terms of pollinating $S$. japonica.

Although $S$. japonica is known as nectariferous orchid (Stpiczyńska et al., 2011), our observations suggested that the amount of nectar secreted was very low, as there was too little to be able to collect it with microcapillary tubes. It is expected that pollinators will learn to avoid non-rewarding plants (Li et al., 2011) and quickly switch to alternative species after only visiting a few non-rewarding flowers (Dafni \& Ivri, 1981). This often results in a low incidence of visits and a lower rate of successful reproduction in deceptive orchids (Neiland \& Wilcock, 1998; Tremblay et al., 2005). For continuously attracting pollinators, the amount of nectar produced by $S$. japonica may not be sufficient. Our records indicate that the pollinators usually visited only one flower of an inflorescence, which partially supports this view. $B$. diversus diversus was, in only one case, photographed consecutively on the same flower. Additionally, although we photographed the entire inflorescence, which consisted of more than 10 flowers, only two $B$. diversus diversus were recorded visiting different flowers in the same inflorescence. Thus, it is likely that $B$. diversus diversus is not so much a geitonogamous as an outcrossing pollinator.

During the course of the flowering season pollinia were removed from $23 \%(9 / 39)$ of the flowers. The number of pollinia deposited was much lower as only 7.7\% (3/39) of the flowers were successfully pollinated. Such low pollination success indicates that spontaneous autogamy does not occur in $S$. japonica, but we did not directly test this by excluding pollinators. Therefore, pollinia vectors are essential for producing seed in natural habitats. The percentage of $S$. japonica flowerspolli- nated $(7.7 \%)$ is relatively low. Production of seed by both nectariferous and nectarless orchids, other than autogamous species (Suetsugu, 2013), is often limited by the low number of visits from pollinators (Neiland \& Wilcock, 1998; Tremblay et al., 2005). However, nectariferous orchids are more successful in producing seed than are nectarless species, and there is a positive association between orchid rarity and lack of a nectar reward for pollinators (Chung \& Chung, 2003). The provision of nectar as a reward for pollinators, on average, doubles the probability of fruit set $(37.1 \pm 3.2 \%$, nectariferous orchids, $\mathrm{n}=84$ and $20.7 \pm 1.7 \%$, nectarless orchids, $n=130$; Neiland \& Wilcock, 1998; Tremblay et al., 2005). The low reproductive success recorded for $S$. japonica also indicates that the amount of nectar it secretes is not sufficient to attract pollinators.

Interestingly, pollinated flowers of Sedirea japonica changed colour from white to bright yellow (Fig. 1A, B). It is thought that the colour change of flowers evolved to enhance the pollination success of plants that visually attract pollinators (Weiss, 1995, 1997; Weiss \& Lamont, 1997; Ida \& Kudo, 2003). Flowers that change colour increase the frequency with which pollinators approach plants by enhancing the attractiveness of individual plants, i.e., long-distance attraction (Niesenbaum et al., 1999; Oberrath \& Böhning-Gaese, 1999). Some studies also report that the colour change of the flowers operates as a cue to deter pollinators from visiting older flowers with little reproductive value; essentially, they are only attractive over shortdistances (Gori, 1989; Weiss, 1991; Niesenbaum et al., 1999; Oberrath \& Böhning-Gaese, 1999). As the colour of melittophilous flowers is often blue or yellow (Faegri \& Van der Pijl, 1979), it is possible that these changes in the colour of the flowers enhance pollination success by visually capturing the attention of bumblebees. This is worth testing in a future study, by determining how yellow-coloured flowers influence the behaviour of Bombus and the reproductive success of the orchid under controlled experimental conditions.

ACKNOWLEDGEMENTS. This research was supported by a Japan Society for the Promotion of Science Research Fellowships for Young Scientists Grant to K.S.

\section{REFERENCES}

Chung M.Y. \& Chung M.G. 2003: The breeding systems of Cremastra appendiculata and Cymbidium goeringii: High levels of annual fruit failure in two self-compatible orchids. - Ann. Bot. Fenn. 40: 81-85.

Cozzolino S. \& Widmer A. 2005: Orchid diversity: An evolutionary consequence of deception? - Trends Ecol. Evol. 20: 487-494.

CRIBB P. 1997: The Genus Cypripedium. Timber Press, Oregon, $301 \mathrm{pp}$.

Cui B., Ma J., Zhang X.Y. \& Yuan X.Y. 2008: Tissue culture and rapid propagation of Sedirea japonica (Linden et Rchb. f.) Garay et Sweet. - Plant Physiol. Commun. 44: 303.

DAFNI A. \& IVRI Y. 1981: Floral mimicry between Orchis israelitica Baumann and Dafni (Orchidaceae) and Bellevalia flexuosa Boiss. (Liliaceae). - Oecologia 49: 229-232.

DARWIN C. 1862: The Various Contrivances by which Orchids are Fertilised by Insects. John Murray, London.

ENVIRoNment AGENCY of JAPAN 2000: Threatened Wildlife of Japan. Red Data Book. Japan Wildlife Research Center, Tokyo, xi + 123 pp. [in Japanese].

FAegri K. \& VAn der PiJl L. 1979: The Principles of Pollination Ecology. Pergamon Press, Oxford, 244 pp.

Gale S. 2007: Autogamous seed set in a critically endangered orchid in Japan: pollination studies for the conservation of Nervilia nipponica. — Plant Syst. Evol. 268: 59-73. 
Garay L.A. \& SweEt H.R. 1974: Orchids of Southern Ryukyu. Harvard University, Cambridge, MA, 180 pp.

Giovanetti M., Cervera J.C. \& Andrade J.L. 2007: Pollinators of an endemic and endangered species, Mammillaria gaumeri (Cactaceae), in its natural habitat (coastal dune) and in a botanical garden. - Madroño 54: 286-292.

GoRI D.F. 1989: Floral color change in Lupinus argenteus (Fabaceae): why should plants advertise the location of unrewarding flowers to pollinators? - Evolution 43: 870-881.

IDA T.Y. \& Kudo G. 2003: Floral color change in Weigela middendorffiana (Caprifoliaceae): Reduction of geitonogamous pollination by bumble bees. - Am. J. Bot. 90: 1751-1757.

Jersáková J., Johnson S.D. \& KindLMAnN P. 2006: Mechanisms and evolution of deceptive pollination in orchids. - Biol. Rev. Camb. Philos. Soc. 81: 219-235.

Kocyan A., Vogel E.F.D., Conti E. \& Gravendeel B. 2008: Molecular phylogeny of Aerides (Orchidaceae) based on one nuclear and two plastid markers: A step forward in understanding the evolution of the Aeridinae. - Mol. Phylogenet. Evol. 48: 422-443.

Li P., Huang B.Q., Pemberton R.W., Luo Y.B. \& Cheng J. 2011: Floral display influences male and female reproductive success of the deceptive orchid Phaius delavayi. - Plant Syst. Evol. 296: 21-27.

NeILAND M.R.M. \& Wilcock C.C. 1998: Fruit set, nectar reward, and rarity in the Orchidaceae. - Am. J. Bot. 85: $1657-1671$

Niesenbaum R.A., Patselas M.G. \& Weiner S.D. 1999: Does flower color change in Aster vimineus cue pollinators? - Am. Midl. Nat. 141: 59-68.

OberRath R. \& Böhning-Gaese K. 1999: Floral color change and the attraction of insect pollinators in lungwort (Pulmonaria collina). - Oecologia 121: 383-391.

Ramírez S.R., Gravendeel B., Singer R.B., Marshall C.R. \& PIERCE N.E. 2007: Dating the origin of the Orchidaceae from a fossil orchid with its pollinator. - Nature 448: 1042-1045.

RoBerts D.L. 2003: Pollination biology: the role of sexual reproduction in orchid conservation. In Dixon K.W., Kell S.P., Barrett R.L. \& Cribb P.J. (eds): Orchid Conservation. Natural History Publications, Kota Kinabalu, Sabah, Malaysia, pp. 113-136.

StPicZYŃsKa M., Davies K.L. \& KamińSKa M. 2011: Comparative anatomy of the nectary spur in selected species of Aeridinae (Orchidaceae). — Ann. Bot. 107: 327-345.
SuEtsugu K. 2013: Autogamous fruit set in a mycoheterotrophic orchid Cyrtosia septentrionalis. - Plant Syst. Evol. 299: 481-486.

Suetsugu K. \& TanaKa K. 2013: Moths visiting the flowers of orchid Platanthera japonica. - Entomol. News 123: in press.

Sugiura N. 1996: Pollination biology of Cremastra appendiculata var. variabilis (Orchidaceae). - Plant Species Biol. 11: 185-187.

Sugiura N. \& Yamaguchi T. 1997: Pollination of Goodyera foliosa var. maximowicziana (Orchidaceae) by the Bumblebee Bombus diversus diversus. - Plant Species Biol. 12: 9-14.

Topik H., YuKawa T. \& Ito M. 2005: Molecular phylogenetics of subtribe Aeridinae (Orchidaceae): Insights from plastid matK and nuclear ribosomal ITS sequences. J. Plant Res. 118: $271-284$.

TREMBLAY R.L. 1992: Trends in the pollination ecology of the Orchidaceae: evolution and systematics. - Can. J. Bot. 70: 642-650.

Tremblay R.L., Ackerman J.D., Zimmerman J.K. \& Calvo R.N. 2005: Variation in sexual reproduction in orchids and its evolutionary consequences: A spasmodic journey to diversification. - Biol. J. Linn. Soc. 84: 1-54.

Tsutsumi C., Miyoshi K., Yukawa T. \& Kato M. 2011: Responses of seed germination and protocorm formation to light intensity and temperature in epiphytic and terrestrial Liparis (Orchidaceae). — Botany 89: 841-848.

WeISS M.R. 1991: Floral colour changes as cues for pollinators. - Nature 354: 227-229.

WeIss M.R. 1995: Floral color change: A widespread functional convergence. - Am. J. Bot. 82: 167-185.

WeISS M.R. 1997: Innate colour preferences and flexible colour learning in the pipevine swallowtail. - Anim. Behav. 53: 1043-1052.

Weiss M.R. \& LAmont B.B. 1997: Floral color change and insect pollination: A dynamic relationship. - Isr. J. Plant Sci. 45: 185-199.

Widmer A., Cozzolino S., Pellegrino G., Soliva M. \& Dafni A. 2000: Molecular analysis of orchid pollinaria and pollinariaremains found on insects. - Mol. Ecol. 9: 1911-1914.

Received October 29, 2012; revised and accepted January 11, 2013 